\title{
RNA Conformation
}

National Cancer Institute

\section{Source}

National Cancer Institute. RNA Conformation. NCI Thesaurus. Code C13449.

Related to the secondary level of structural organization of RNA. RNA can be found in various conformations, including double- as well as single-stranded, and in loops. 